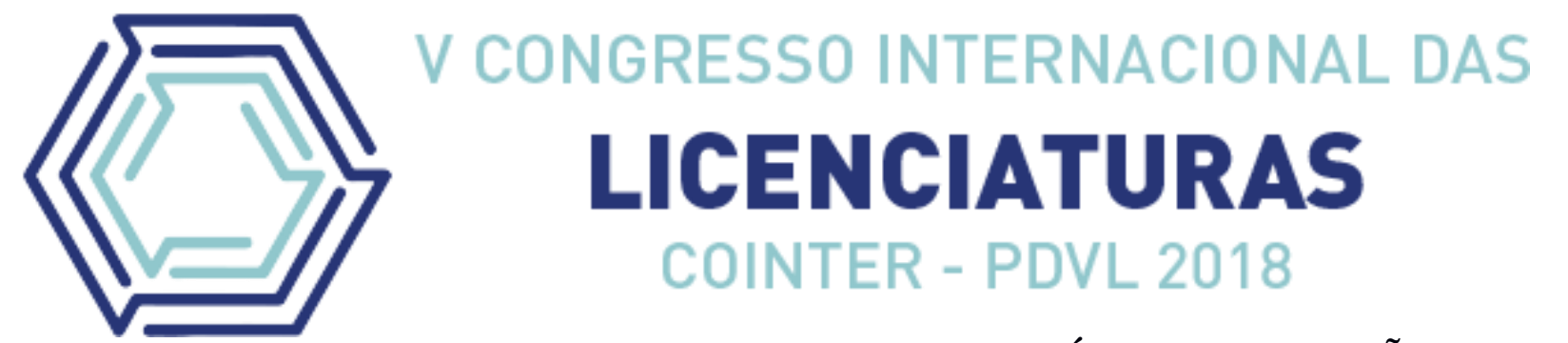

\title{
O SOLO E O SUBSTRATO: UM MODELO DIDÁTICO DE VULCÃO NA TERRA PRIMITIVA
}

\section{THE SOIL AND SUBSTRATE: A DIDACTIC MODEL OF VOLCANO IN PRIMITIVE LAND}

\author{
Apresentação: Relato de Experiência \\ Ana Clara Silva Araújoํㅜㄹ Flávia Renara Moraes da Silva ${ }^{1}$; Marcela Oliveira de Sousa ${ }^{1}$; \\ Vanessa Cardoso Pereira ${ }^{1}$ Marlúcia da Silva Bezerra Lacerda ${ }^{2}$
}

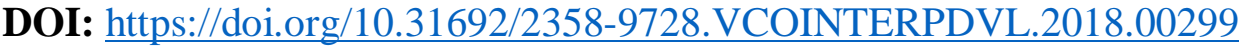

\section{Introdução}

Pouco de diferente é feito para tornar a aula mais atrativa e que motive os alunos a aprender e construir seu próprio conhecimento, o que acaba levando-os a perder o interesse por certas disciplinas, os recursos utilizados geralmente são quadro, pincel e datashow o que acaba deixando a aula com a mesma rotina, não chamando a atenção dos alunos para os conteúdos abordados. Segundo Paulo Freire (1996) ensinar não é, absolutamente, a transferência de conhecimento, mas deve ter suas atenções voltadas para fazer com que o aluno tenha condições para produzir ou construir o conhecimento. Entendemos que para isso acontecer devem ser criadas condições em sala de aula que instiguem os alunos a buscar, dentro de si, motivações de aprendizagem e estar aberto às curiosidades dos alunos em relação ao tema da aula.

Quando o recurso utilizado demonstra resultados positivos, o aluno torna-se mais confiante, capaz de se interessar por novas situações de aprendizagem e de construir conhecimentos mais complexos.

Embora as atividades experimentais sejam uma necessidade, sua utilização em sala de aula é inexpressiva no ensino fundamental e raríssimo no ensino médio (GASPAR, 2003). A

\footnotetext{
${ }^{1}$ Discentes do curso de Licenciatura em Ciências Biológicas do IFPI/Campus Teresina Central-Email: flaviarenara27@gmail.com

${ }^{2}$ Docente orientadora do curso de Licenciatura em Ciências Biológicas do IFPI/Campus Teresina Central. Email: marlucia.lacerda@ifpi.edu.br
} 
experimentação em sala de aula é uma intervenção pedagógica que permite a aproximação dos alunos e contribui com a aprendizagem destes, pois os resultados os impressionam e, também, os motivam.

O trabalho aqui vivenciado é parte de uma atividade de disciplina do curso de Licenciatura em Ciências Biológicas do Instituto Federal do Piauí (IFPI), Campus Teresina Central, a partir da análise de uma coleção de livros didáticos, onde o livro didático utilizado foi "Projeto Apoema Ciências 6, $2^{\circ}$ edição". Intitulado por representação vulcânica em terra primitiva. Com o objetivo de facilitar o processo de aprendizagem acerca do tema, propondo também uma atividade de fácil produção e que pudesse ser utilizada por outros professores da rede pública de ensino, sendo um material multidisciplinar, pois é possível elencar muitos conteúdos no pequeno ecossistema criado. Nas disciplinas de ciências, geografia, química e história.

\section{Relato de Experiência}

Inicialmente delimitamos o público alvo a que seria destinado a atividade, fora proposto o tema a partir da análise de livros didáticos de uma mesma coleção, optamos por realizar atividade para alunos do $6^{\circ}$ ano ensino fundamental, depois foi pesquisado os tipos de deficiências e foi escolhido qual seria trabalhado no projeto. A atividade desenvolvida foi concretizada a partir da análise do livro didático, e sob o tema eixo: Terra e Universo, escolhido por meio de sorteio. Escolhemos trabalhar com a unidade que o autor do livro descreve a terra e o solo: o solo e o subsolo, a princípios tivemos dificuldade em escolher o tema principal, pois este eixo possui uma gama de possibilidades, decidimos fazer uma maquete da terra primitiva, demonstrando com o experimento do vulcão, simulando um ecossistema inóspito.

Para tornar a aula mais dinâmica e atrativa, existem diversos recursos que podem ser utilizados pelos professores, contribuindo para a aprendizagem e motivação dos alunos. Nesta proposta foi construído um modelo didático com uma estrutura base de vulcão, onde foi reutilizando papel jornal e copos plásticos no centro para colocar o líquido da reação, que depois foi modelado com gesso para que ficasse mais resistente e com possibilidade de uso em novas situações. O gesso foi opção usada em substituição à argila, que era a alternativa sugerida no protocolo original. Foram feitas depressões de gesso que simulavam montanhas e lagos ao modelo com acréscimo de rochas e areia coletadas no jardim da instituição para dar 
um aspecto natural a composição. Utilizou-se ainda tinta marrom no vulcão para contribuir no efeito de sombreamento.

A realização de experimentos, em Ciências, representa uma excelente ferramenta para que o aluno faça a experimentação do conteúdo e possa estabelecer a dinâmica e indissociável relação entre teoria e prática. (REGINALDO et al., 2012). Tais recursos ajudam no desenvolvimento da aprendizagem dos alunos, pois são meios de motivá-los e envolvê-los ao conteúdo que está sendo discutido, proporcionando, assim, uma melhor compreensão e interpretação do que está sendo trabalhado. Neste sentido, buscamos dar mais enfoque ao tema, foi confeccionado e adicionado um globo de isopor no canto da maquete para simular as camadas da Terra, com o objetivo de demonstrar de onde vem o magma da erupção, o que facilitaria ainda mais a explicação do conteúdo pelo professor e a compreensão do mesmo pelos discentes.

Validando o modelo didático, foi realizada uma experiências para simulação da erupção vulcânica. No teste da erupção do vulcão fez-se a reação química com ácido acético, anilina, sabão e bicarbonato de sódio que simulava o magma vulcânico e que poderia ser uma representação de um vulcão em atividade para melhor ilustração, análises e reflexões sobre as consequências deste fenômeno, tanto para a estrutura atual dos aspectos geológicos do planeta como para o meio ambiente. Souza (2007) ressalta que é possível a utilização de vários materiais que auxiliem a desenvolver o processo de ensino e de aprendizagem, isso faz com que facilite a relação professor - aluno - conhecimento.

Figura 1: Atividade Experimental de construção da maquete do vulcão na disciplina de Instrumentação para o ensino de Ciências. Fonte: Própria

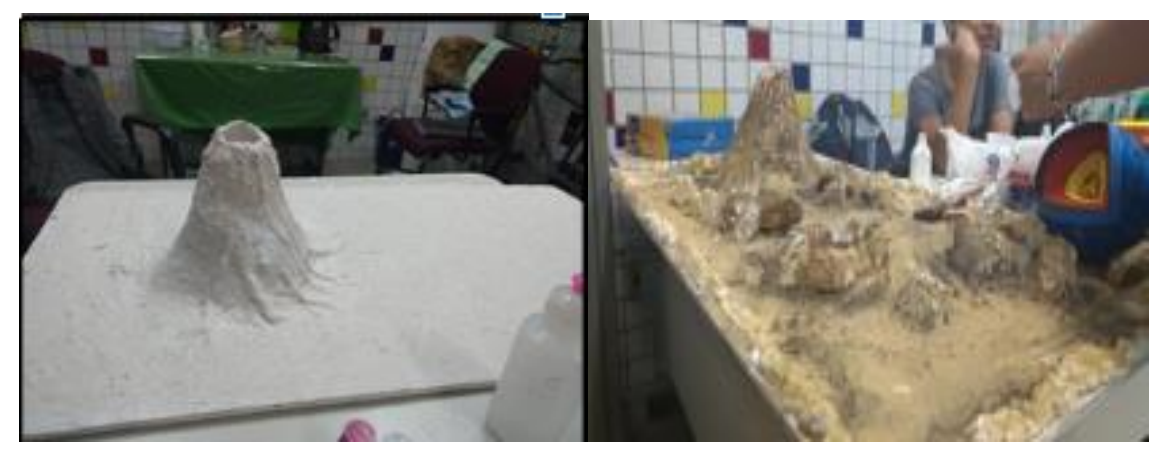

\section{Considerações finais}

A utilização de recursos didáticos no processo de ensino aprendizagem dos alunos possibilita um aprendizado com mais significado, pois a utilização destes recursos faz a 
diferença e é possível tornar as aulas mais dinâmicas, possibilitando que os alunos sejam sujeitos mais ativos no processo e compreendam melhor os conteúdos e que, de forma interativa e dialogada, possam desenvolver sua socialização e sua criatividade.

Este trabalho apontou como grande fonte de aprendizado aos licenciandos e futuros docentes que, principalmente, desenvolveram mais nos aspectos de organização, planejamento e testagem do modelo, conduzindo o processo passo-a-passo em cada etapa para que findasse em resultados satisfatórios e próximos do que era esperado.

Percebeu-se ainda que um material didático simples, porém bem feito, pode contribuir em muito no aprendizado, buscando com criatividade fazer ajustes e adaptações, tornando o aprender e o ensinar ainda mais interessante.

\section{Referências}

FREIRE, P. Pedagogia da autonomia: saberes necessários à prática educativa-Paulo Freire54 Edição- Rio de Janeiro: Paz e Terra, 1996.

PEREIRA, A. M. Projeto Apoema Ciências 6, 2. ed. São Paulo. Editora do Brasil. 2015. 368 p.

REGINALDO, C. C.; SHEID. N. J.; GULLICH, R. I. C. O ensino de ciências e a experimentação. In: SEMINÁRIO DE PESQUISA EM EDUCAÇÃO DA REGIÃO SUL, 9, Caxias do Sul, 2012. Anais... ANPED SUL. Disponível em: $<$ http://www.ucs.br/etc/conferencias/index.php/anpedsul/9anpedsul/paper/viewFile/2782/ 286>. Acesso em 07 jul. 2016

SOUZA, S. E. O uso de recursos didáticos no ensino escolar. In: I ENCONTRO DE PESQUISA EM EDUCAÇÃO, IV JORNADA DE PRÁTICA DE ENSINO, XIII SEMANA DE PEDAGOGIA DA UEM, Maringá, 2007. Arq. Mudi. Periódicos. Disponível em: $<$ http://www.pec.uem.br/pec uem/revistas/arqmudi/volume 11/suplemento 02/artigos/01 9.df>. Acesso em: 22 mar. 2016. 